\title{
The COMCAT Chronicles: The North Carolina Community Colleges Union COM Catalog Project
}

\author{
Linda S. Halstead
}

During 1982, deliberations of the Automations Committee of the North Carolina Community College Learning Resources Association included discussion of a possible major project. As the automation trend approached our libraries, the Automations Committee, in its leadership role for the community college system, was immediately concerned that some colleges under pressure to begin library automation might undertake projects that did not adhere to MARC standards. The committee was also apprehensive that automation systems might be chosen which would inhibit future networking capabilities.

In March, 1983, upon a recommendation from Shirley McLaughlin, LRC Director for Asheville-Buncombe Technical College, the Automations Committee adopted a COM catalog project. Marge Lindsay, then networking consultant from the North Carolina State Library, and Vera Fessler, a representative from General Research Corporation, offered valuable information and support to the committee in making decisions concerning the project.

The committee decided that a COM catalog project would allow libraries to begin working toward automation by building a data base in standard MARC format. This data base could be updated by loading Solinet records made available through the North Carolina Community College Media Processing Services. Further, this project would give the committee additional time to study automation systems and formulate recommendations for library automation. The COM catalog would be a useful by-product allowing libraries to provide inexpensive microform copies of catalogs to off-campus teaching locations. This would benefit students on these campuses and help the colleges comply with new Southern Association of Colleges and Schools criteria requiring services at off-campus sites. The

\footnotetext{
Linda S. Halstead, Librarian at Central Carolina Technical College in Sanford, is Chairman of the North Carolina Community College Learning Resources Association Automations Committee, 1982-84, and Project Coordinator for The North Carolina Community Colleges Union COM Catalog Project, 1983-85.
}

committee members also felt that a union catalog might enhance the chances for outside funding while improving interlibrary loan services among participating colleges. As a consortium, they could be assured of better prices from vendors; and the consortium would serve as a vehicle for training and support as other colleges endeavored to develop COM catalogs.

In addition, the committee decided to send a questionnaire to all learning resources centers in the community college system to ascertain interest in the project if, by chance, full or partial funding were available. When results of the questionnaire were obtained, a proposal to Occupational Education Research Services in the Department of Community Colleges would be submitted.

General Research Corporation (GRC) was selected as the vendor because of time constraints in submitting the proposal and the immediate availability of price information. Also, possible advice and support were available from Caldwell Technical Community College personnel, who had also chosen GRC as their COM vendor. Committee members had good reports about GRC, and had heard horror stories about conversion projects through other vendors. GRC had offered special consortium prices, and the committee felt it would be best to keep to a minimum the number of vendors building different data bases within the community college system. Using the same vendor would be less complicated in the long run and improve networking and system compatibility.

The committee sent out 58 questionnaires in March. Thirty-five of these were returned. Twenty-two colleges were interested in the project if it were fully funded, and ten were interested even if partial funding were available. Since only limited funding was available from Occupational Education Research Services, these ten institutions were contacted to determine their willingness to participate. Nine colleges were included in the proposal: Asheville-Buncombe Technical College, Central Carolina Technical College, Central Piedmont Community College, Guilford Technical Community College, Rowan Technical College, Sampson 
Technical College, and Wilson County Technical Institute.

The proposal was delivered in June, and in August the committee was notified that the project was not funded. A meeting was held that month at Central Carolina Technical College to decide whether or not to proceed with the project. Central Carolina Technical College offered to serve as the coordinating/billing agency for the consortium. The decision was made to organize independent of the Learning Resources Association. Those institutions that wished to be included in the consortium were asked to notify the project coordinator by September 15 .

\section{As work progresses, it is impor- tant to keep up with the edit- ing process.}

The original eight project institutions were Asheville-Buncombe, Brunswick, Carteret, Central Carolina, Guilford, Rowan, Sampson, and Wilson. In September the consortium members discussed the COM catalog process, decided how often catalogs would be produced, who would be the contact person at each institution, and if any other union products were desired. By late September, a contract was received from GRC, and in mid-October the consortium members met at Central Carolina Tech to develop parameters which would determine the appearance of the catalogs. In November the members met at Guilford Technical Community College for a training workshop led by personnel from Caldwell Technical Community College. The parameters and final contract were then mailed to GRC.

The new year brought new members for the consortium. Vance-Granville Community College and Cape Fear Technical Institute joined in January and Craven Community College in April. The first input was sent by Wilson Tech in February 1984. Most of the other original eight institutions began inputting in March and April. In May, Media Processing Services offered to conduct MARC workshops for the members. This helped to conquer fears about MARC coding. Several meetings were held throughout the year to discuss the progress of the project and problems being encountered.

By January 1985, the consortium members were feeling fairly confident about the system when GRC informed the group that they would be phasing out the present method of input and changing to microcomputer input through their new software, COM/QUEST. This announcement caused considerable panic. A few institutions were happy with the change, but most were concerned about requesting more equipment money as well as adjusting to a new system. In February, the decision was made to contact other vendors and explore other available options to reassure the consortium that GRC was the best vendor for the project.

In March 1985, Media Processing Services requested Solinet archive tapes which were available for the period of August 1983 through December 1984. During the LRA Conference in March, subcommittees were organized to review vendor proposals and to do research on COMCAT orientation for patrons and staff.

In June, Media Processing Services notified the consortium that they were subscribing to archive tapes for all the community colleges, allowing records to be extracted for COMCAT updates. A meeting was held at Carteret Technical College for a GRC COM/QUEST demonstration. This demonstration and the report of the subcommittee studying vendor proposals resulted in the decision to retain GRC as the project vendor.

During the summer, consortium members worked frantically to complete their data input before the final cut-off date in September. Only three colleges finished inputting their monographs entirely. The others plan to complete monographs during the coming year, clean up the inevitable errors, complete authority work, and, in most cases, input audiovisual collections. Some of the members who began to use QUEST during the summer rush were surprised and pleased with the speed of the new process.

In October, the colleges received their COM catalogs. Union catalogs were also mailed. The following month, Shirley Gregory, Librarian at Wilson Tech, became project coordinator. Southeastern Community College was welcomed into the group as a new member of this growing consortium.

Membership in the consortium is flexible, allowing new members to join at any time. To join the consortium, a college contacts the project coordinator, who sends the new member information and helps to establish parameters and procedures. The new member sends the coordinating institution a letter of commitment agreeing to be responsible for its share of the costs of the project.

In addition to responsibilities for the orientation of new members, the project coordinator handles day-to-day problems, serves as liaison 
between the vendor and consortium members, disseminates information about the project, serves as a general resource person, calls meetings when required, and bills members for their share of the NCCC Union COM Catalog Project invoice from GRC.

Some questions that need to be addressed before considering a COM catalog project concern the physical and human requirements, the procedures, the cost, customer support, and the potential for finding a match, or hit, with the bibliographic records available in the vendor's data base. These questions can be answered from the experience of the NCCC Union COM Catalog Project with General Research Corporation only. A questionnaire was sent to the project participants to aid in the formulation of answers to these questions.

Concerning the question of physical requirements, initially the inputting process required an IBM Selectric typewriter equipped with a special typing element, special ribbon density, and special computer paper designed for optical character recognition (OCR) typing. Computer errors resulted from wrinkles, spots, or flaws in the paper, faulty ribbons, or poorly corrected typing errors.

GRC later phased out this system and advised the consortium that the new contract of November 1, 1985 would require the use of their COM/QUEST software. The hardware required for QUEST included: an IBM-PC compatible microcomputer, PC-DOC 2.0 or later, with $256 \mathrm{~K}$ of memory; a single disk drive; monitor; and a 1200 baud modem. No problems occurred from using a telephone line through the college switchboard. This line was specially programmed to allow direct long distance dialing for inputting COM catalog data, on-line searching through Dialog, and electronic mail.

Concerning the question of personnel, the project places a heavy load on staff. In a small library, it is difficult to take on any other projects while conversion is under way. This was the most frequent negative response mentioned by project participants. Three questionnaires were not received from the consortium members; but of those received, six replied that they had hired additional staff. In all but one institution this was a full-time position or the equivalent in part-time personnel.

It is, perhaps, ideal to have one full-time person responsible for the whole procedure. Participants found that the person need not be a professional. Clerical personnel were trained very successfully to fill the position. It is more important that the person hired be someone who is detail conscious and capable of sustaining interest and attention through the often boring periods of straight numerical input. In answering a question concerning how comfortable the person felt doing MARC coding, all replied that once the person actually became involved and had some experience coding some records, they lost their initial fears and began to feel quite comfortable.

Several of the participants had problems with turnover among staff members assigned to the project, which resulted in additional time spent in training new personnel. Because of the temporary nature of the position, it would be wise to expect to lose personnel to permanent positions elsewhere. One of the project participants suggested training a back-up person for each project task. If the person is not a professional, then professional time must be allotted to answer questions resulting from coding records and from problems discovered through editing the bibliographic record retrieved from the data base. If the record which was pulled from the vendor's data base to match an ISBN or LCCN does not precisely correspond with the shelf list card, decisions must be made about whether the differences are acceptable. A record of decisions made would help this editing process proceed more smoothly while assuring consistency and helping to eliminate repeat questions.

Of the eight institutions returning questionnaires, five utilized work-study students. They were given tasks such as inventory, matching edit sheets and shelf lists, proofing, typing, looking up ISBNs and LCCNs, filing, and sorting. Union members changing to LC classification during the conversion process also trained students in re-labelling cards and books.

As a rule of thumb, the following procedures apply for most conversion projects. Begin by weeding the collection. Don't waste valuable time inputting materials that should be discarded. Then take an inventory of the collection to avoid including materials that are missing. If the shelf list does not have an ISBN or LCCN, check the books during the inventory process. Most vendors use these numbers to match books with bibliographic records in their data base. The project participants were instructed to prefer an LCCN over an ISBN when inputting and an ISBN on a card over one in a book when they were different. The COMCAT group consulted the following sources to locate numbers: the book itself, Books In Print, the union microfiche for the Kansas Network (provided by GRC), American Book Publishing Record, the Dialog Remarc data base, and Media Processing Services. Based on our own ex- 
perience at Central Carolina Tech, coding a record was quicker than consulting several sources. Only the book and the Kansas Network microfiche were checked. Later in the project, many problems were solved through the assistance of Media Processing Services staff, saving the participants many hours of searching and coding. If a change to LC classification is contemplated, remember when checking for ISBNs and LCCNs to record a call number that might appear in the book or on a union list if one does not appear on the shelf list card.

The next step is to begin inputting records, making sure to record what has been done with each bibliographic item. For example, was a LCCN typed or was it an original entry, has it been edited, was it xeroxed and sent somewhere for searching, etc.? The Record Control Number was circled or written on the shelf list when the checking was completed. This Record Control Number is the number assigned to the bibliographic record in the data base and must be used when updating or deleting a record. At Central Carolina the project staff made an initial pass through our card catalog, inputting all records which showed an ISBN or LCCN. Through the editing process the staff could then become more comfortable with a MARC record. One of the other colleges input their collection by completing one shelf list drawer before beginning another.

The Library of Congress published MARC Formats for Bibliographic Data, a helpful reference for use in MARC coding decisions.

As the work progresses, it is important to keep up with the editing process. It is so easy to get behind in the beginning when a large percentage of the collection is being input. This is especially true when using the method of entering all available ISBNs and LCCNs at once. In planning deadlines, remember to allow extra time at the end of the project for final clean-up and authority work.

Vendor costs averaged 25 cents per record. Those schools responding to the questionnaire reported costs were very close to their budget estimates. The vendor costs included data base maintenance, input charges, edit lists, freight charges, production costs for 14 union catalogs and an average of 8.64 individual catalogs, authority control for a few schools that had completed their authority work, cross references, software licensing, user manuals, and the supplies used in the beginning of the project for OCR input. These figures do not include staff and equipment costs which have varied from institution to institution. The union catalog is expensive to produce; however, consortium members share other costs, such as data base maintenance and software licensing. Having the union catalog for interlibrary loan purposes is an obvious benefit to the participants.

Customer support from GRC was excellent. They provided a toll-free number, and were willing and available to answer all questions. When problems were discovered, they helped solve them.

The union catalog is expensive to produce; however, consortium members share other costs such as data base maintenance and software licensing. Having the union catalog for inter library loan purposes is an obvious benefit to the participants.

Shirley McLaughlin determined, with a few edit lists remaining to be checked, that AshevilleBuncombe Tech had averaged spending approximately 9.5 minutes per title. With the first college inputting in February 1984, four more beginning in March, three more in April, and one more in May, by July the colleges had entered 53 percent of the records that would comprise our data base fourteen months later. There are two reasons for this. First, most of the participants went completely through their shelf list catalog inputting ISBNs and LCCNs before tackling problems. Secondly, project staff members were not at this time heavily involved with editing. Five of the colleges responded that their staff had coded an estimated average of 17.4 percent of their collection for original input.

Seven of the eight institutions responding to the questionnaire stated that the project had taken longer than planned. Comments were: "Such projects USUALLY take longer than anticipated." "No previous experience upon which to base time requirements." "Staff changes required retraining ..."

The project went faster and smoother for those libraries that chose not to convert their collections from Dewey Decimal classification to the Library of Congress system. Their staff had less difficulty matching edit lists and did not have to spend time looking for classification numbers 
which did not appear on the data base record. However, only one institution that had chosen this time to reclassify its collection had second thoughts about the decision. The majority felt that this was the best time to complete this additional project, and that the LC classification system was better suited to technical collections. Some libraries had several shelves of books for a particular curriculum classified in one truncated Dewey number. Many of the call numbers had changed through different editions of Dewey. Since a change in classification was considered necessary, it would be best to incorporate this process into the project. Staff and patrons would then have time to become familiar with the new system before automation required a further adjustment. If automation seems traumatic for some people in any case, the less complicated the process the more likely the new technology will be accepted by both staff and patrons.

\section{The final data base report showed an overlap of holdings of only 30.6 percent.}

The final data base report showed an overlap of holdings of only 30.6 percent. This relatively small percentage was surprising given the fact that the collections are small and contain many of the same reference books. Also, there is duplication of curricula among many of the colleges.

Since the first union catalog and individual COM catalogs were delivered in October 1985; it is still too early to assess the impact of the union catalog on interlibrary loan activities as well as to determine the acceptance of the COM catalog by library patrons. In most cases, the colleges are still in the process of changing old Dewey book labels to the Library of Congress call numbers appearing on the COM catalog. Patrons who have used the COM catalog, however, seem to be accepting the new format.

It is expected that the union catalog will expedite the response time for interlibrary loans by allowing each college to call directly the library owning requested material and have it delivered through the state courier. Many of the institutions have already joined the North Carolina Educational Computing Service's Mail/News service and plan to use this for interlibrary loan requests and messages. With subject access to collections, the consortium members can now fill many requests previously referred to libraries outside of the community college system. This will strengthen our already strong cooperative ties and may lead to further networking.

At the beginning of the project library personnel expressed various rationales for converting to a COM catalog: a first step towards automation; a desire to be ready to participate in area and statewide networking; easy conversion to LC classification; elimination of manual labor involved in catalog card maintenance resulting from revisions of Dewey, AACR II, new filing rules; elimination of filing cards altogether; provision of multiple catalogs in various locations; elimination of space problems in housing additional card catalogs; and provision of a union catalog for interlibrary loan.

The project was a new challenge and a learning experience for all of the consortium members. Each of the participants has gained valuable information that it is willing to share with others contemplating a conversion project.

Although the group reports having a stressful year, they were fortunate to have library staff members who could see the advantages of the project. At meetings, the positive attitudes of the members were impressive. The project participants felt that automation was imminent and wanted to be prepared to take advantage of it as soon as it became feasible for them. It is, perhaps, understandable that in technical and community colleges many librarians are open to new technology. When automation reaches us, we will be standing with our magnetic tape in hand, ready and waiting and waiting and waiting....

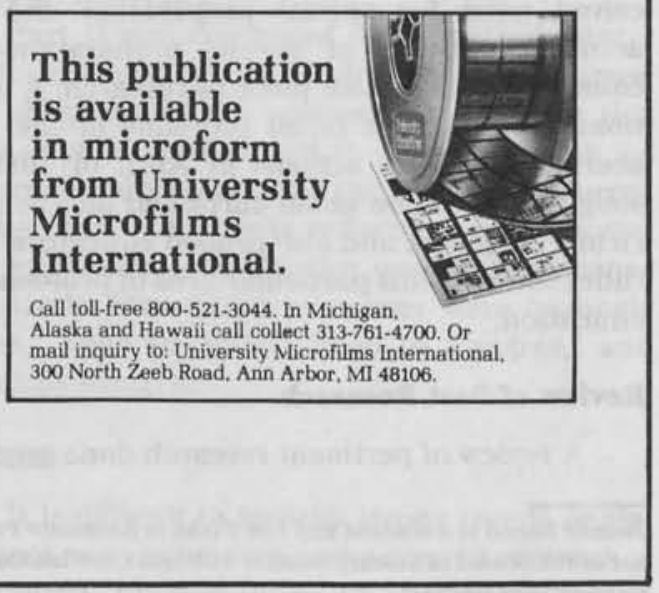

